\title{
6 \\ Support as intervention in decision processes
}

\author{
G. de Zeeuw \\ Centre for Innovation and Cooperative Technology \\ University of Amsterdam \\ Valckenierstraat 65, 1018 XE Amsterdam \\ The Netherlands \\ Tel: +31 20 5256338, Fax: +31 205255778 , \\ e-mail:zeeuw@phys.uva.nl \\ J. G. Schuurman \\ Technical University of Twente \\ Faculty of Instructional Technology \\ P.O.Box 217, 7500 AE Enschede \\ The Netherlands \\ Tel: + 3153 4894201, Fax: +31534892895 \\ e-mail: schuurman@edte.utwente.nl
}

\begin{abstract}
People's activities tend to deviate in many ways from what are considered 'rational' theories of decision making. In trying to interpret these deviations increasingly complex theories have been formulated. The deviations may also be interpreted, more simply, as a falsification of the method used for their study. This paper suggests a different approach to the study of decision making: decision theory should be considered as an element of the class of action languages, that is of languages that support the improvement of individual and collective actions.
\end{abstract}

\section{Keywords}

Decision, support, research, language, qualification, skill, collective, actorship 


\section{INTRODUCTION}

Decision theory aims to help people improve on their action, by adding the possibility of a choice. The theory formalises the option of comparing actions and choosing or selecting what in some way is 'best'. This option may be implemented in different ways: with the help of a decision analyst, or through organisations that help clients access the resources needed to make a choice. Machines that are programmed to do the same are among such organisations: they can help to retain the observations and produce the events that people need to make decisions.

It is in the sense of adding a choice that one can say that decision theory was developed to support people. It was intended as a theory for improving on actions. It aims to help explore available resources and to formulate recommendations for their use. To accept such support will require some guarantee that an improvement can be realised. A guarantee implies the notion of quality. Two forms may be distinguished. One is based on the notion of qualification. The other on the notion of skill. Both types are needed-together and interactively.

Qualification refers to the insight that adding a choice is an act of choice itself: it may detract as well as add to one's actions*. One may come to regret-postdecisionally-the choice made, in the same sense that one may come to regret the use of the wrong medicine. There are other reasons for lack of quality: one may not be sufficiently skilled, and unable to capture exhaustively the resources to use, or to select what is 'best'. Lack of skill usually implies that learning to use decision theory did require too much effort, so one may become too hasty in making choices.

The literature on decisions seems mainly concerned with increases in skill, and not with qualification. People are assumed to be qualified under any circumstance. This suggests that decision theory is not used as a theory for people to add choices to their actions, but as a theory of individuals who make decisions. This suggestion is in line with the questions that researchers have tried to answer: how well do people do in comparison to the theory, when do people deviate from the theory (Klein et al, 1992, Beach and Lipshitz, 1992; Tversky and Kahnemann, 1981)?

Lack of attention to qualification may explain the ambiguity that often appears to creep into the interpretation of results. What if decision makers do not automatically structure improvement in terms of decision theory (Watson, 1992)? What if people deviate from what the theory prescribes? Without knowledge of qualifications no judgement of skill is possible. Without it one can detect deviations, but not explain them-except through vague notions like personal experience or context. And also, if one can not predict deviations, one will be prone to find additional ones.

The issue of qualification is not restricted to the notion and techniques of decision making. Doubts have been expressed regarding the possibility of qualification in

\footnotetext{
* The so-called 'frame-problem' is well-known in the field of artificial intelligence (Boden, 1979). An early statement of the issue of qualification appears in De Zeeuw and $W$ ).
} 
operational research and in cybernetics (Taket and White, 1993; Rosenhead, 1989), as well in problem solving (De Zeeuw, 1993*). Each discipline appears able to boast examples where users appear qualified without apparent effort. Each also has to admit to cases where becoming qualified seems to be rather an arbitrary, highhanded affair, requiring one to impose or 'force' people to qualify.

Organisations provide many examples of 'forcing' people into pre-defined qualifications. Given their prevailing division of labour they assign the task of making decisions. In this case, if employees become skilled in the techniques of decision making (such as estimating probabilities, assessing values and computing recommendations), they must be high quality decision makers-as they then combine both qualification and skill. The organisation that originally bestowed the qualification may go broke, of course, having divided its labour ineffectively.

In recent years the possibility of turning the results of decision research into support has developed into an industry. However, preferring the search for theories of, over theories for, does not seem to have been a detour only. It still is part of the present academic interest, as opposed to a sole interest in support as theories for (although there is attention to friendly computer interfaces: Larichev, et al., 1990). This has important implications, including the possibility that the industry is one which aims first to 'program' people to qualify as decision makers, second to provide the tools they then need**.

In this paper we will consider how to avoid this form of imposition as well as judge the quality of what is offered. This implies having to explore approaches to research which take the notion of qualification as central. Such research obviously will not be classical, as the latter assumes that qualifications are 'given' (by nature). It also may not be research, in the sense that it may prove impossible to suggest qualifications that are not in some way preferred by the researcher, identifying the latter as a politician rather than a researcher. Fortunately as it turns out, there is an in between.

The paper is set up as follows. First, we will introduce two examples to clarify the role of qualification (section 2). Secondly, we will re-interpret the examples in terms of classical science, and present a re-formulation of the re-interpretation to facilitate thinking about it (section 3). Thirdly, we will indicate some consequences: what the reformulating implies in terms of the process of research (section 4), and in terms of the characteristics of its results (section 5). Finally, and by way of a conclusion, the argument of the paper is summarised (section 6).

\footnotetext{
* The issue of qualification as regards problem solving has been dismissed by Newell (1990).

** The analogy with the tobacco industry seems unavoidable.
} 


\section{EXAMPLES}

In this section we present two examples that appear extreme relative to the notion of research. The first example derives from the work of Fischhoff (1992). It is intended to show that research that interprets decision theory as a theory of individual behaviour fails in the sense that support in terms of a theory for would have been more appropriate. The second example deals with an area similar to that explored by Fischhoff. The example does not make use of decision theory, although the results of the study also were intended to support improvement of action.

Fischhoff (1992) is interested in supporting women to prevent or evade rape. He proceeds by assuming that women are to be seen as instances of some "hypothetical individual', acting as a decision maker. The instances will differ among themselves of course but will have some common characteristics: by increasing their decision making skills they will be able to improve their actions and prevent being harmed. Fischhoff intends to provide recommendations concerning what alternatives to choose, what probabilities to estimate, what values to assess.

The first step involved collecting possible options-from which to develop advice-from the literature as well as from various groups of people: (female) 'students at the University of Oregon; alumnae of the University (all over $\mathbf{4 0}$ years of age); and mothers belonging to a parenting program, largely from low-income homes. We also had samples from male students, paralleling the female ones, and samples of sexual assault experts, drawn nationally from private consultants, criminal justice personnel, counsellors, and researchers' (p. 579).

The resulting set of 'options for reducing the chance of being raped' totalled more than 1,100 . Next it was attempted to reduce this set in terms of 'good' decision making, by re-writing each option as advice to "Doing action $X$ in order to achieve intended effect $Y^{\prime \prime}$. It was tried to identify consequences $Y$, and to estimate their probabilities, for example on the basis of reports from women in 'rape crisis centres, self-defence instructors, hospital emergency room personnel, crime reporters, sex offender therapists, and national victimisation surveys'.

It proved impossible to perform a 'comprehensive analysis', and 'infeasible' to find one advice or strategy (or a small set) which could be 'believed to reduce the risk of rape', and nothing else. There was no 'best possible strategy for a particular individual in a particular situation', in the form of 'simple rules, capturing some of the wisdom of decision theory, which they [the women] might apply to their personal situations'. The material collected did not show how becoming more skilled as a decision maker might help to prevent or evade rape.

This failure is especially striking as there was no warning. Proper research procedures were followed. The number of observations was sufficient to apply the usual methods of analyses, without the need for further observations. The study even can be seen as more extensive than standard studies in the area. A reason for the failure is suggested however. Each woman herself might have to '[c]onsider where [she] might fit in' the material collected, rather than accept classification by the researcher as an instance of the 'hypothetical' decision maker. 
This suggestion appears to indicate that Fischhoff in the end changed his mind. Women came to be seen as users rather than instances. They are not the object of study, nor their actions. They become the addressees: their understanding and subsequent action depends on whether they feel addressed by some advice (counsellors and others might feel addressed as well). Recommendations thus should now serve mainly as an 'aid in coping with [a stressful topic]', and as injunctions to 'keep thinking', or organise 'one's thinking'-in a process of awareness raising.

The difficulties Fischhoff encountered appear to be due to the use of decision theory as a theory of. He recognises that his users reject this and take his results as a context to express themselves, that is as a theory for, or a suggested qualification. His recommendations thus became a system, an entity that survives only given that it is used by users. Survival therefore is not guaranteed. It is in the interest of the system to make access free (users do not 'pay'), and to honour use-by helping to structure 'one's thinking' (the system 'pays'). This becomes explicit in the following example.

Van den Berge et al (1980) consider the plight of homosexual men who run the risk of being beaten up by 'potenrammers', people who gang up with the explicit purpose of harming them. Their plight is somewhat similar to that of the women in Fischhoff's study. They do not want to be beaten up, but also do not want to prepare themselves by becoming experts in karate, or by not making use of streets and parks. The cost of the latter type of preparation is seen as too high-as would be the cost of 'reduc[ing] men's propensity to rape', and of 'creat[ing] full employment', suggested in the Fischhoff study.

Van den Berge et al (1980) do not assume homosexuals to be decision makers. They rather become 'qualified' as 'victims'-by the hunter-like behaviour of the 'potenrammers'. As victims they appear unable to think of anything but being beaten. It seemed necessary to change this 'qualification', rather then to make the homosexuals more skilled-in running, or in fighting, or in getting protection. It turned out that there were anecdotes about this change. These were collected, as many as possible, and rewritten while being tested on 'ease of understanding', 'grippingness', etc.

One of the anecdotes is about someone who is walking alone in the park. When noticing that he attracts the attention of some 'potenrammers', he starts to dance and flap his arms and yell 'Pewit, I am a bird'. His assailants walk away in disgust. $\mathrm{He}$ is mad, and no longer of interest. The change implies a change in qualification: from homosexual 'victim' to 'mad person'. This change requires little training and physical investment, but has large (and desirable) effects. A selection from the anecdotes was published. Some 1500 copies were sold in Amsterdam.

Interviews with some of those who had bought a copy indicated that the effect was as intended. The anecdotes were not interpreted as (repeatable) solutions to a problem or as general strategies. Rather, they introduced a 'way of thinking'. This was facilitated by their form or structure: a situation was described, then a danger, then a change in the interpretation, then the surprising consequences of the change. 
Anecdotes are, of course, quite near to the 'moral tales' that help people use to 'extract lessons' (as Fischhoff mentions). Most cultures cherish them.

After some years the anecdotes.no longer were talked about in Amsterdam. Also, if there was any lasting reduction in the number of beatings, this effect may have been due to more general social changes or become embedded in them. The study is summarised here only as it shows an approach opposite to Fischhoff's study: the authors aimed to address people so they might adapt their qualifications to become 'instantly' skilled using their experience. The authors did not intend to train people in skills they might lack assuming a fixed social 'qualification' (such as a lack of strong friends).

\section{RESEARCH AND QUALIFICATION}

The paper by Fischhoff has been published in a high status journal (the American Psychologist). It is set well within the academic tradition. Adherence to that tradition is confirmed when Fischhoff claims that 'one should no more expose people to untested advice than to untested medicine' (p. 583). But in the end his work seems to burst out of that tradition. His concluding statements rather apologetically claim results to be but an 'aid to coping', 'lessons', something to be 'considered'-statements one would not expect in connection to tested medicine.

Van den Berge et al clearly start where Fischhoff ends. The authors aim to provide lessons, and to reduce the effort people must invest in learning skills. They end by realising something at least very akin to their aim. Still, they did not achieve high academic status (although there have been related studies: Vahl, 1992; Van Haaster, 1991; Guinée, 1994; Kline, 1979). One reason may be that they did not 'burst out' of anything. From the start they intended to order their observations (responses in the form of stories) on the basis of a pre-selected and pre-conceived form, that of the anecdote.

Their approach clearly differs from the traditional one, although there are similarities: it does emphasise the need to order observations, to find out which observations belong together and can be combined into higher quality observations (e.g. averages, and theories). However, it does not stress the need to observe what makes observations belong together itself, as one would need to observe a 'scientific object'. It does not require that the ordering (as anecdotes) be chosen by 'nature', or reality*. This leaves the choice of an ordering more or less open.

One might conclude therefore that the work of Van den Berge et al is not scientific, or at least that it does not obviously fit the traditional mode. The authors chose the form of what makes observations (answers from respondents) belong together (the anecdote). This form is not an observable object itself therefore. The

* The notion of reality should not be taken as indicating some epistemological position. Wagenaar (1974 
study thus does not satisfy the criteria of what is 'demarcated' as science and is not within the 'agreement or convention' proposed by Popper and others (for example Popper, 1959). Still, its results do not appear to be entirely useless.

It is possible to interpret the approach differently therefore. Anecdotes do transfer something when used as an 'aid in coping', as a 'lesson', etc. They even do two things: they address users, thereby orienting and qualifying them to express themselves in certain ways and not in others; they also indicate in what way the addressees can become skilled in expressing themselves. In this interpretation it is not the anecdote which is to be made visible. It is the way anecdotes make it possible for users to find coherence in new experiences, and to show and express what they can do.

At the basis of this type of expression is a linguistic structure or language, therefore: the double form of the anecdotes. Sentences in this language suggest qualifications as well as how to become skilful. Advice (as implied in the anecdotes) is thus not the same as a medicine and can not be tested as a medicine. It is not a particular effect one is after, but rather a change in a development, with a variety of effects. Or in other words: one does not test the consistency of the way the body's mechanism reacts to an input, as in the case of medicine, but rather its flexibility.

The notion of a language is not entirely strange to traditional science (Kuhn, 1962). Its results address users-who are thereby shown how to identify some object (become qualified to do so), and to observe variation in the properties of the objects' instances (become skilled to do so). To describe results in this way the language of variables is used. In terms of its purpose this language is effective and efficient. There are some dangers as well. Its use can impose 'objectness' as an inflexible qualification, in particular when it proves impossible to identify objects in a more traditional sense.

To deal with this type of situation other languages developed. They do not impose objectness, but rather allow their users to express themselves as if they are objects. Users thus have to maintain their 'objectness' themselves, but also may choose a language that helps to realise objects with preferred properties. This suggests the possibility of a test as in traditional science: whether for example the form of an anecdote (and its instances) can help addressees to 'express' themselves and not get beaten up. If anecdotes fail this test one should look for other forms.

Awareness of the importance of 'addressing' seems to be relatively general. For example, it often happens that the results of a commissioned study are not usedwhich can be explained through the notion of 'addressing' (Vahl, 1992). Usually commissioners are familiar only with the language of variables. Results thus may become based on an imposition of objectness. When they are made available, employees may disagree, and start to modify what 'belonged together'. The more they achieve their own preferred expression, the more they reduce the validity of the commissioned results. 
The dangers involved in un-informed 'addressing' seem especially clear in the case of organisations 'undergoing profound change', and having to re-structure in the 'transition'. Members may feel addressed both by proposed structures and by the 'theory for' needed to realise those structures. They may resist or comply with the qualifications involved. A series of interactions between individuals thus may ensue in which none of the earlier qualifications remains, so all previous skills become useless. The organisation may be worse off than before.

Humphreys and Kirtsoglou (1997) note the ubiquity of 'addressing' in all social spheres. They describe for example how a drug peddler is outfaced by a client in daily life. Two types of languages appear involved. One is the language of scarcity: the drug peddler not only manipulates prices but also the expectations of those he will sell to. The client uses the language of access: she indicates that she is used to better quality than is being sold. When she succeeds in having the peddler accept her 'qualification', he loses the one in which he was skilled, and has to lower his prices.

The use of a language implies a collective in which the language is used. Members of this collective can be addressed and will respond. They can not be taken for 'objects' of traditional science, but the collective can. The more observations on the collective begin to belong together, the more stable the members of the collective respond to each other. This implies that the collective can be studied in the way of traditional science. Results will include what language is used to establish the collective, and how this language relates to other, desired properties of the collective*.

Although it could be argued that the study by Van den Berge et al is not inside science, the above seems to show that this is predicated mainly on the anecdotes themselves being seen as scientific 'object'. Another interpretation takes the collective of the addressees of the anecdotes as the object. Each addressee will be qualified in terms of the collective. If the distribution of qualifications stabilises, the collective stabilises. The anecdote quoted above describes for example how to become qualified as 'mad': by creating and stabilising a collective mainly through the use of body language.

Decision theory has been argued to fail when studied as a theory of decisions concerning rape (section 2). It can be re-interpreted as a theory for in the sense of Van den Berge et al's anecdotes. This would lead to studies of the properties of the collective that results when its members address and qualify each other ás decision makers. It is the form of decision theory that matters here, not the content. The 'aid in coping' should thus be tested in terms of its ability to influence the attacker's 'thinking', to change and add a choice to the attacker's actions (Beach, 1993; Steier, 1991).

* As is to be expected a number of such languages has developed, in daily life and elsewhere, without explicit testing in research. An interesting example is the language using the notion of system: it is used in research, as well as in the development of collectives that seem to have little connection with research, for example based on the use of certain techniques (Checkland and Scholes, 1990, and others). 


\section{FORMS OF RESEARCH}

The re-interpretation in the previous section suggests that one see the results of the study by Van den Berge et al (1980) as 'scientific', and those from the Fischhoff (1992) study as 'failed scientific', or possibly as non-scientific, in contrast to what appeared to be the case at first sight. The results of the latter study seem to be due to a too uncritical use of decision theory as a theory of. This kind of use warranted various apologies, the gist of which was that the results should function only as stimulants, to highlight what is useful in the experience of their users.

The re-interpretation makes use of the notion of a collective. Although this could be interpreted as a 'scientific' object, it clearly does not refer to such an object in the traditional sense. It becomes such an object only if it certain events take place. Members have to address each other and to be addressed. This process is expected to result in two types of observable effects: the development of the collective, and of some stabilising form of exchange. It is the latter which now can be described as a theory for. It refers to what happens inside the collective.

A number of consequences may be noted, for example a partial reversal of the roles of observation and action in research. Traditional research is interested only in what can be described by a theory of. It is not interested in the use of such a theory, that is in theories for action which are based on theories of. In the re-interpreted approach there is such an interest: to create a collective one has to find a suitable theory for, suitable in the sense that it allows for the development of a theory of the resulting collective*. This theory may then be used in any action, that is become part of any theory for.

One may also consider the following. A basic element in traditional research is the search for high quality observations X, Y, Z, etc. Results take the form of statements in the language of variables: 'if observation $X$, then observation $Y$ ', given some object. Note that nothing is said about the improvement of action, only of observation. This is different in the re-interpreted form. Members of a collective aim to change their actions and observations and improve on them in the sense of achieving a preferred expression. Results take the form: 'if observation $\mathrm{X}$, do action $A^{\prime}$.

There is a big difference between the two types of statement. The first relates only to improved observations. These may support action, for example by making better visible when to do something. They can not say anything about action itself however, that is about its goals. The second relates to observations as well as actions. The former can be made 'better' if they 'belong together' given a particular action. The latter can also become 'better': if they contribute to establishing the collective. In this approach increasing quality is not restricted to observation.

We may re-consider decision theory in terms of the two types of statements. It takes as its output an action, that one that is selected from a set of actions. It takes

\footnotetext{
* This relation may be used as a criterion as well. The notion of orthogonality has been introduced (Higo, 1996; De Zeeuw, 1997).
} 
as its input a series of estimates, that is of observations that may influence the choice of the action. These observations are taken to belong together in terms of the action to be taken. Statements in decision theory thus have the form: if observation X, do action A-precisely the form of what should help establish a collective. What does not seem to be clear yet is what properties this collective will have (Klein, 1992).

This formulation can be related to the way Fischhoff formulates advice: 'doing action $[A]$ in order to achieve intended effect $Y$ '. This form emphasises the effects of action A, made visible as high quality observations $Y$. In contrast the form 'if $X$, do $A^{\prime}$ specifies resources inside the collective, but does not indicate any immediate effects of $A$, as these may differ substantially from the effects of all $A$ together*, that is from what is expressed through the collective. The link between the two types of effect is indirect**, rather than direct as Fischhoff seems to assume.

This separation of the immediate and mediate effects of actions by the members of a collective has an interesting consequence. The immediate effects should be usable only inside the collective. The mediate in any action, by anybody, including the members of the collective. If the latter are to profit from the mediate effects these should be full expressions of what the members can do, and should not be manipulated by them to be useful only for their actions inside the collections. In other words, being member of a collective should help avoid being corrupt****

Not becoming corrupt is not guaranteed, of course. Members may decide to defect from the collective, for example when they find the effort to maintain the collective too heavy. It will be the task of research to discover what language will minimise defection, and thus will be 'best' to prevent corruption. In an important series of experiments Axelrod (1984) seems to have demonstrated that defection is minimal when the language does not imply some stop or end to the collective. If the end would be known, members might prefer to defect before others do.

Although the differences between the traditional and the re-interpreted form of science are extensive, there also are similarities. Notions like objects and qualifications clearly are of a comparable nature, as are properties and skills. Both have similar roles. The first two notions relate to what can be generalised; the second two to what summarises the particular. A division of qualifications in a collective bestows actorship on its inside, given the constraints imposed by the collective, and also allows objectship to be achieved on the outside.

\footnotetext{
* This is the case especially when the number of participants is large.

* * This difference is related to the notion of 'pluralism', as defined but not studied by Jackson (1990).

*** Although not explicitly developed to be used in this context, the notion of 'closure' may be mentioned here: it is used to indicate for example that what makes observations belong together should be observable itself.
} 


\section{JUDGING QUALITY}

Even after noting that Fischhoff's (1992) work failed, and that his recommendations seem but apologies for this failure, it still may be rated highly, for two reasons. Firstly, the observations he collected are thought provoking. Secondly, he did create a story, or a series of lessons that people might do well to take to heartnotwithstanding the cost of implementing advice such as 'never drive alone'. This raises the question how to judge good advice. The most obvious source is to look at advice from the point of view of the re-interpreted approach to research.

Although there is no precise and generally accepted 'demarcation' to research, there is some consensus as to what it aims for. Results should not be characterised in terms of who is going to, or is allowed to use them. Later results should improve on earlier ones, that is it should be possible to accumulate results. Use should be inexpensive in the sense that further testing can be reduced (Rosen, 1993). It is on these criteria that Fischhoff's results seem to score relatively low, and those of Van den Berge et al relatively high (see previous section).

This raises the question how to achieve results that realise these aims-in all cases where one has to cope with disruptions, or breakdowns, such as being attacked or molested, having to face the competition, etc. Some suggestions seem in place. We will summarise them in terms of four puzzles (De Zeeuw, 1995): what observations to start from, how to operate on them to achieve high quality observations, how to justify them, and how to combine high quality observations so they satisfy the above criteria, e.g. not to exclude pre-specified groups of users.

The first suggestion is to interpret the notion of observation quite broadly. It may refer to any statement by those who are to participate in the research. Their quality should be increased in the process. This implies finding rules of the form 'if observation X, do A', for each participant. They may be found by introducing some language having this form, in the way of hypotheses, or by allowing participants to discover their own preferred language. When a collective develops, one should note its properties: what languages go together with what other characteristics.

The next step in the research process is of course to test whether rules that developed in one collective can be used to develop collectives elsewhere. Note that it may be possible that collectives develop that are not considered supportive in the sense used here: they do not necessarily lead to improvements of action that do not require effort, and are 'free' to all participants. Testing will be extremely important therefore: there may be a difference between what helps in the case of 'breakdowns', or to express new and culturally useful abilities.

This approach to research has a distinct Darwinian flavour. Results may increase in quality: languages may be found with growing 'carrying power', where what is 'carried' is a-speedy, effortless-recognition of what others in the collective do. Collectives based on such languages should be stable in many circumstances. This is not to say of course that progress will only go in the direction of generality: there may be languages that turn out to be 'best' in some circumstances, next to languages that have a wide range of applicability (as has the language of variables). 
Returning again to the decision language, Watson (1992) has noted, for example, that in practice it often is replaced by other languages ('theories') that are characterised by the fact that they help to decrease the information processing load for users, or distribute memory requirements among those involved. The same type of development can be found in Fischhoff's work (Fischhoff, 1992; appendix B). General forms of advice such as 'question universal recommendations', or 'recognise lay expertise' no longer take the form of the language of decisions.

\section{CONCLUSION}

The starting point of this paper was the observation that although the origin of decision theory is supportive (a theory for rational action), the notion of support seemed to have been lost relatively early. Efforts to develop decision support still seem to be based on the interpretation of decision theory as a theory of rational action. An example was presented: the work of Fischhoff (1992). This interpretation seems to lead to failure, to ever larger numbers of variables (Beach, 1993). It was noted that there is a need for a return to the original notion of support to improve action.

To exemplify ways of satisfying this need another example was considered: the development of anecdotes as support systems. It was argued that the use of anecdotes may be considered 'non-scientific', but also that it can be seen as scientific. This re-interpretation makes heavy use of the notion of a collective, the inner structure of which is regulated by a language, and the outer structure of which is observable and can be used as a resource. These notions were developed in some detail, including the form which the languages may take.

In this way an answer was found to a dilemma: that Fischhoff's results have a high academic status but also seem to represent a failure of accepted research practice. The answer clarifies the characteristics of support systems, as well as how such systems may be implemented. The major shift it introduces concerns the transfer of observations: one should distinguish between transfer inside and outside a collective. Suggestions were made on how to stabilise this distinction: languages with high 'carrying power' can help to create new collectives out of those that face some breakdown.

\section{REFERENCES}

Axelrod, R. (1984) The evolution of co-operation. Basic Books, New York. Beach, L. R. (1993) Four revolutions in behavioural decision theory, in Leadership theory and research: perspectives and directions (eds. M. M. Chemers and R. Ayman) Academic Press, San Diego. 
Beach, L. R. and Lipshitz, R. (1992), Why classical decision theory is an inappropriate standard for evaluating and aiding most human decision making, in Decision making in action: models and methods. (eds. G. A. Klein, J. Orasanu, R. Calderwood, and C. E. Zsambok) Ablex, Norwood.

Berge, F. van den, Bossewinkel, W., Groeneveld, S., Muis, M. and Wildschut, H. (1980) Flikkers en agressie. Universiteit van Amsterdam, Amsterdam.

Boden, M. (1979) Artificial Intelligence and Natural Man. Basic Books, New York. Checkland, P. and Scholes, J. (1990) Soft systems methodology in action. Wiley, Chichester.

Fischhoff, B. (1992) Giving advice: decision theory perspectives on sexual assault. American Psychologist, 47, 577-588.

Guinée, I. (1994) Leiding nemen als optie. Thesis Publishers, Amsterdam.

Haaster, H. van (1991) Wartaal. Een onderzoek naar methoden van competentieverhoging in de geestelijke gezondheidszorg. Thesis, Amsterdam.

Higo, H. A.-W. (1996) Research-based action in the process of socio-economic development in Sudan. Unpublished Ph.D. University of Lincolnshire and Humberside, Lincoln.

Humphreys, P. and Kirtsoglou, E. (1997) Violence within the post-structural economy of shortage. Unpublished manuscript, London School of Economics, Department of Social Psychology.

Jackson, M. C. (1990) Beyond a system of systems methodologies. Journal of the Operational Research Society, 41, 657-668.

Klein, G. A, Orasanu, J. , Calderwood, R. and Zsambok, C. E. eds. (1992) Decision making in action: models and methods. Ablex, Norwood.

Klein, G. A. (1992) Twenty questions-suggestions for research in naturalistic decision making, in Decision making in action: models and methods. ( eds. G. A. Klein, J. Orasanu, R. Calderwood, and C. E. Zsambok), Ablex, Norwood.

Kline, E. (1979) Planning side-effects, in Problems of context, (eds. G. de Zeeuw and P. van den Eeden), Free University Press, Amsterdam.

Kuhn, T. S. (1962) The structure of scientific revolutions. University of Chicago Press, Chicago.

Larichev, O. I., Mechitov, A. I., Morgoev, V. K., Moshkovich, H. M. and Furems, E. M. (1990) .Exact duplicates of human judgements, in Contemporary issues in decision making. (eds. K. Borcherding, O. I. Larichev and D. M. Messick), North Holland, Amsterdam.

Newell, A. (1990) Unified theories of cognition. Harvard University Press, Cambridge, MA.

Popper, K. R. (1959) The logic of scientific discovery. Harper \& Row, New York.

Rosen, R. (1993) Some random thoughts about chaos and some chaotic thoughts about randomness. Journal of Biological Systems, 1, 19-27.

Rosenhead, J. (ed.) (1989) Rational Analysis for a problematic world. Wiley, Chichester.

Steier, F. (ed.) (1991) Research and Reflectivity. Sage, London. 
Taket, A., and White, L. (1993) After OR; an agenda for postmodernism and poststructuralism in OR. Joumal of the Operational Research Society 44, 867-883.

Tversky, A. and Kahnemann D. (1981) The framing of decision and the psychology of choice. Science 211, 453-458.

Vahl, M. (1992) Stories and scientific enquiry, in Cybernetics and systems research '92. (ed. R. Trappl), World Scientific, Singapore.

Watson, S. R. (1992) The presumptions of prescription. Acta Psychologica, 80, 7-31.

Zeeuw, G. de and Wagenaar, W. A. (1974) Are subjective probabilities probabilities?, in The concept of probability in psychological experiments. (ed C.A. Stael von Holstein), Reidel, Dordrecht.

Zeeuw, G. de (1993) Increase of competence via shared workspaces. Systems Practice, 6, 155-173.

Zeeuw, G. de and Vahl, M. (1994) Intervention and Research. Technical Report CICT, Amsterdam, TR/94-46.

Zeeuw, G. de (1995) Values, Science and the Quest for Demarcation. Systems Research , 12, 15-25.

Zeeuw, G. de (1997) Knowledge acquisition in changing realities (accepted for publication in Kybernetes, October 1997).

\section{BIOGRAPHIES}

Gerard de Zeeuw is Professor of Complex Social Systems at the University of Amsterdam, Faculty of Mathematics, Computer Science, Physics and Astronomy. He studied at the Universities of Leyden, Rotterdam, and Stanford and did his Ph.D. at the University of Amsterdam. Twice he was a fellow of the Netherlands Institute for Advanced Studies. He is Visiting Professor at the London School of Economics and at the University of Lincolnshire and Humberside. He has published extensively, for example Model denken in de Psychologie.

Jan Gerrit Schuurman studied Experimental Psychology at the University of Groningen, and will finish his Ph.D. in 1998 at the University of Enschede, Faculty of Educational Science and Technology. He is interested in transfer: of skills, of knowledge, of ways of thinking. He has developed TILT, a computer game to study the development of co-operation. 